\title{
Alveolar Soft Part Sarcoma: Progress Toward Improvement in Survival? A Population-Based Study
}

\section{Tomohiro Fujiwara ( $\boldsymbol{\nabla}$ tomomedvn@okayama-u.ac.jp )}

Okayama University Graduate School of Medicine

\section{Eiji Nakata}

Okayama University Graduate School of Medicine

\section{Toshiyuki Kunisada}

Okayama University Graduate School of Medicine

\section{Toshifumi Ozaki}

Okayama University Graduate School of Medicine

\section{Akira Kawai}

National Cancer Center Hospital

\section{Research Article}

Keywords: metastasis, therapeutic, encourages, sarcoma, chemotherapy

Posted Date: October 11th, 2021

DOI: https://doi.org/10.21203/rs.3.rs-948320/v1

License: (a) (i) This work is licensed under a Creative Commons Attribution 4.0 International License. Read Full License 


\section{Abstract}

Background: Alveolar soft part sarcoma (ASPS) is a rare histological subtype of soft-tissue sarcoma, which remains refractory to conventional cytotoxic chemotherapy. We aimed to characterize ASPS and investigate whether the oncological outcome has improved over the past decade.

Methods: One hundred and twenty patients with newly diagnosed ASPS from 2006 to 2017 were identified from the Bone and Soft-Tissue Tumor Registry in Japan. The Kaplan-Meier estimate and Cox proportional hazard model were used to investigate the survival outcomes and factors affecting prognosis.

Results: The study cohort comprised 34 (28\%) patients with localized ASPS and 86 (72\%) with metastatic disease at presentation. The 5 -year disease-specific survival (DSS) was $68 \%$ for all patients and $86 \%$ and $62 \%$ for localized and metastatic disease, respectively $(p=0.019)$. Metastasis at presentation was the only adverse prognostic factor for DSS (hazard ratio [HR]: 7.65; $p=0.048)$. Patients who were $>25$ years $(80 \% ; p=$ $0.023)$, had deep-seated tumors ( $75 \% ; p=0.002)$, and tumors $>5 \mathrm{~cm}(5-10 \mathrm{~cm}, 81 \% ;>10 \mathrm{~cm}, 81 \% ; p<0.001)$ were more likely to have metastases at presentation. In patients with localized ASPS, adjuvant chemotherapy or radiotherapy did not affect survival, and 13 patients (45\%) developed distant metastases in the lung ( $\mathrm{n}=$ $12,92 \%$ ) and brain ( $n=2,15 \%)$. In patients with metastatic ASPS (lung, $n=85$ [99\%]; bone, $n=12$ [14\%]; and brain $n=9[11 \%])$, surgery for the primary or metastatic site did not affect survival. The use of pazopanib significantly prolonged survival in patients who received systemic treatment $(p=0.045)$, whereas doxorubicin-based cytotoxic chemotherapy did not. Overall, a trend toward improved DSS for metastatic ASPS has been observed since 2012 (5-year, 58\%-65\%; $p=0.117$ ), when pazopanib was approved for use in advanced disease.

Conclusion: The national study confirmed a unique feature of ASPS with frequent metastasis to the lung and brain but an indolent clinical course. An overall trend toward prolonged survival after the introduction of targeted drugs encourages continuous efforts to develop novel therapeutic options for this therapeutically resistant soft-tissue sarcoma.

\section{Introduction}

Alveolar soft part sarcoma (ASPS), first described by Christopherson et al. in 1952 [1], is a rare histological subtype of sarcoma, accounting for approximately $0.5 \%-1 \%$ of all soft-tissue sarcomas [2, 3]. ASPS primarily affects younger patients, with a peak incidence age of $15-35$ years [2,3], and female predominance is well documented [1, 4-6]. Indeed, Surveillance, Epidemiology, and End Results Program data analysis revealed that $72 \%$ of patients were aged $<30$ years, and $58 \%$ were females [3]. ASPS commonly originates from deep soft tissues of the extremities [1, 7-9], predominantly the lower extremities, followed by the trunk, but may also arise from the head and neck, internal organs, tongue, and bone [5, 7, 10-15]. Clinically, ASPS presents as a slow-growing, painless mass with high vascularity [6], carries a high rate of early distant metastasis [16, 17], and is characterized by resistance to conventional cytotoxic chemotherapy [18]. Molecular studies have identified a specific translocation, der (17)t(X;17)(p11.2;q25), which results in an ASPSCR1-TFE3 gene fusion [6]. Despite the advances in basic research, no effective treatment has been devised, especially for advanced disease. 
Although ASPS is refractory to conventional cytotoxic chemotherapy, this tumor is a targetable sarcoma [19]. The ASPSCR1-TFE3 fusion gene leads to aberrant transcription of hypoxia-inducible factor 1a (HIF-1a), which upregulates proangiogenic factors, including vascular endothelial growth factor (VEGF) and hepatocyte growth factor receptor (MET/HGFR), and induces immunosuppression in the tumor microenvironment [20, 21]. These molecular features have encouraged the exploration of targeted therapy, such as antiangiogenic drugs and immune-stimulating therapy [19]. Anti-VEGF receptor tyrosine-kinase inhibitors, such as pazopanib, regorafenib, and axitinib, have shown modest antitumor activity $[19,22,23]$, among which pazopanib has been approved for the second-line or later treatment of patients with advanced soft-tissue sarcomas in Japan since 2012 [24]. The immune checkpoint inhibitors against PD-1, PD-L1, and CTLA-4, have also shown modest activity in several clinical trials for soft-tissue sarcomas [25, 26]. A phase II trial of axitinib (anti-VEGF receptor tyrosine-kinase inhibitor) plus pembrolizumab (anti-PD-1 inhibitor) showed promising results, with a partial response observed in 55\% of participants and stable disease in 18\% [27]. Clinical trials of the anti-PD-1 inhibitor nivolumab (NCT03277924) and anti-PD-L1 inhibitor atezolizumab (NCT03277924) are currently under investigation for advanced ASPS. However, the overall survival outcome in patients with ASPS and the nationwide impact of the introduction of these novel therapies remain unknown.

Therefore, the purpose of this study was to characterize ASPS using the Bone and Soft-Tissue Tumor Registry (BSTTR) Database of Japan and investigate whether the oncological outcomes have improved since the approval of the targeted drugs. To clarify the effect of evolution in the treatment modality, we conducted our analyses using two cohorts comprising patients with localized and metastatic ASPS.

\section{Patients And Methods}

\section{Data source}

The primary data source for this study was the BSTTR Database in Japan. This database is a nationwide organ-specific cancer registry for bone and soft-tissue tumors, which was headquartered in the National Cancer Center Hospital and funded by the Japanese Orthopaedic Association (JOA). Data were collected from 89 JOA-certified hospitals, in which the registration of data is mandatory, and other hospitals, in which the participation of data registration is voluntary. The data are updated annually. This study was approved by the Institutional Review Board of the JOA.

\section{Study population}

Patients with a diagnosis of ASPS were searched in the registry from 2006 to 2017. A total of 181 patients were identified in the database. The inclusion criteria were patients who were newly diagnosed with pathological confirmation. Thus, we excluded 45 patients who were registered after previous treatment elsewhere and 1 patient who was not histologically diagnosed. Fifteen patients without any data required for analyses or whose follow-up period was $<12$ months (if they were alive) were also excluded.

\section{Outcomes and covariates}

The primary outcome of the study was disease-specific survival (DSS). The following details were extracted from the database: basic demographics (age, sex, status at the first visit [newly diagnosed or referral after 
initial treatment elsewhere], and date of referral); tumor-related information (date of diagnosis, method of diagnosis [pathologically or clinically diagnosed], tumor grade, tumor site, tumor depth, metastasis at the time of diagnosis, and site of metastasis); treatment-related information (surgery for primary site, surgery for metastatic site, use of systemic therapy and radiotherapy, and regimen of systemic therapy); and information regarding the outcome at the last follow-up, including oncological outcome. Patients were restaged according to the American Joint Committee on Cancer (AJCC) TNM staging system, eighth edition [28]. The surgical margin was registered according to the system by Enneking et al. [29] as radical, wide, marginal, or intralesional margins.

\section{Statistical analysis}

The Kaplan-Meier method was used to estimate the DSS and metastasis-free survival (MFS), and the differences were calculated using the log-rank test. DSS was defined as the period between the date of diagnosis and tumor-related death. Patients who died of other causes were considered as censored at the time of death. MFS was defined as the period between the date of diagnosis and the date when the distant metastasis was found. Any factor influencing the prognosis in the univariate analysis was analyzed in the multivariate analysis using the Cox proportional hazard regression model. Correlations between clinicopathological variables and localized/metastatic disease were compared using the chi-square test or Fisher's exact test. The threshold for statistical significance was $p<0.05$. All analyses were conducted using SPSS version 23 (SPSS, Inc., Chicago, IL).

\section{Results}

\section{Clinical characteristics and survival outcomes for all patients}

The study cohort comprised 120 patients with newly diagnosed ASPS. The demographic and tumor characteristics are summarized in Table 1. The median age of the patients was 27 years (interquartile range [IQR], 21-34 years). There was a slight female predominance in this cohort; $42(35 \%)$ patients were male, and $78(65 \%)$ were female. The most frequent site of involvement was the lower extremity $(n=74 ; 62 \%)$, followed by the trunk $(n=34 ; 28 \%)$, upper extremity $(n=11 ; 9 \%)$, and head and neck $(n=1 ; 1 \%)$. The median tumor size was $7.0 \mathrm{~cm}$ (IQR, 5.4-10.0 cm), and most tumors were located deep to the fascia $(n=113 ; 94 \%)$. Clinically, 34 (28\%) patients presented with localized disease and $86(72 \%)$ with metastatic disease. According to the AJCC staging, $16(13 \%)$ presented with stage II disease, $13(11 \%)$ with stage IIIA, $5(4 \%)$ with stage IIIB, and 86 (72\%) with stage IV. The mean follow-up period was 31.5 months (range, 1-128 months).

Overall, the 3 - and 5-year estimated DSSs were $86 \%$ and $68 \%$, respectively (Figure $1 \mathrm{~A}$ ). The univariate analysis revealed that the presence of metastasis at the time of diagnosis was the only factor significantly associated with worse DSS ( $p=0.019$; Table 1) (present: HR, 7.65; 95\% confidence interval [Cl], 1.02-57.28 versus absent: $\mathrm{HR}, 1 ; p=0.048)$. The clinical characteristics according to the presence of distant metastasis at diagnosis are shown in Table 2. Patients who were older than 25 years (80\%; $p=0.023)$, had deep-seated tumors $(75 \% ; p=0.002)$, and had tumors $>5 \mathrm{~cm}(5-10 \mathrm{~cm}, 81 \% ;>10 \mathrm{~cm}, 81 \% ; p<0.001)$ were more likely to have metastatic disease at the time of diagnosis (Table 2). The treatment patterns and survival outcomes of patients with localized versus metastatic disease were analyzed separately. 


\section{Treatments and survival outcomes in patients with localized ASPS}

Thirty-four patients presented with localized ASPS at the time of diagnosis. Most patients $(n=29 ; 85 \%)$ underwent surgical excision. Patients without surgical treatment $(n=5)$ were excluded from further analyses (Table 3). The treatment approaches used for these patients primarily comprised local therapy alone ( $n=27$; 93\%). Twenty-five patients received surgery alone, and two patients underwent surgical excision plus adjuvant radiotherapy. Two patients received neoadjuvant/adjuvant chemotherapy: one received neoadjuvant chemotherapy followed by surgery plus adjuvant radiotherapy and one underwent surgery followed by adjuvant chemotherapy. The surgical margins achieved were wide in 26 (90\%), marginal in 2 (7\%), and other (radical) in 1 (3\%). No local recurrence was recorded during the study period.

The 3- and 5-year estimated DSSs were 100\% and 86\%, respectively (Figure 1B). The univariate analysis revealed that tumor size $>5 \mathrm{~cm}$ was significantly associated with worse DSS $(p=0.021)$. The surgical margin, the administration of neoadjuvant/adjuvant chemotherapy, and use of radiotherapy did not affect the DSS (Table 2).

During the study period, 13 patients (45\%) developed distant metastases. The sites of metastasis were the lung in 11 patients, lung + brain in 1, and brain in 1 (Figure 2A); lung and brain metastases developed in 35\% and $6 \%$ of patients with localized ASPS, respectively. The 3 - and 5-year estimated MFSs were 55\% and 18\%, respectively. Univariate analysis revealed that the use of cytotoxic chemotherapy was negatively associated with MFS $(p=0.014)$. Neither the surgical margin nor the use of adjuvant radiotherapy affected the MFS.

\section{Treatments and survival outcomes in patients with metastatic ASPS}

Eighty-six patients presented with metastatic ASPS at the time of diagnosis. The sites of metastasis at diagnosis were lung in 60 patients, lung + bone in 9, lung + brain in 8, lung + lymph node in 3, lung + softtissue in 2 , bone in 1, lung + liver in 1, lung + bone + brain in 1, and lung + bone + spleen in 1 (Figure 2B): lung metastases were observed in 85 patients (99\%), bone metastases in 12 (14\%), and brain metastases in 9 $(11 \%)$.

Local treatment of the primary site of the tumor was performed in 59 of 86 patients with metastatic ASPS (69\%): surgery alone in 55 patients (64\%), surgery + radiotherapy in 2 (2\%), and radiotherapy alone in 2 (2\%). The surgical margins achieved in patients who underwent surgical excision were wide in 51 patients (90\%), marginal in 4 (7\%), intralesional in 1 (2\%), and unavailable in 1 (2\%). Surgery for metastasis was performed in 11 patients (13\%), radiotherapy was administered palliatively in 9 (11\%), and systemic treatment was performed in 48 (56\%): conventional cytotoxic chemotherapy in 14 (16\%), targeted therapy in 19 (22\%), conventional cytotoxic chemotherapy + targeted therapy in 11 (13\%), and unknown regimen in 4 (5\%). Regimens of the systemic treatment are summarized in Supplementary Table 1. The doxorubicin (DOX)based cytotoxic chemotherapy regimens were administered in 23 of 25 patients who received conventional cytotoxic chemotherapy (92\%). Pazopanib was administered in 27 of 30 patients (90\%) who received targeted therapy. The proportion of patients who underwent systemic treatments for metastatic ASPS has significantly increased since $2012(49 \%$ versus $62 \%$; $p=0.002)$, when the use of pazopanib was approved by 
the government, and, accordingly, conventional cytotoxic chemotherapy was performed less frequently ( $41 \%$ versus $19 \% ; p=0.002)$.

The 3- and 5-year estimated DSSs were $80 \%$ and $62 \%$, respectively (Figure 1B). The median survival period in patients with metastatic ASPS was 69 months. The univariate analysis revealed that the tumor depth at the primary site was associated with survival outcome; deep-seated ASPS was significantly associated with worse DSS (5-year, $63 \% ; p=0.006)$. Surgical resection of the primary $(p=0.559)$ or metastatic site $(p=$ $0.143)$, receipt of radiotherapy $(p=0.614)$, and administration of systemic therapy $(p=0.470)$ did not affect the DSS. Among the 44 patients with available data on the type of systemic drug, we observed no significant difference in DSS according to the type of therapeutic drug. The 5-year DSS was $34 \%, 66 \%$, and $55 \%$ in patients who received cytotoxic chemotherapy, targeted therapy, and cytotoxic chemotherapy + targeted therapy, respectively $(p=0.535)$. In terms of the therapeutic regimen, patients who received DOX-based cytotoxic chemotherapy regimens had significantly inferior DSS; the 5-year DSSs were $39 \%$ and $75 \%$ in patients with and without DOX-based cytotoxic chemotherapy regimens, respectively ( $p=0.033$; Figure 3A). Of note, patients who did not receive DOX-based cytotoxic chemotherapy regimens were mostly treated with pazopanib $(n=20 / 21 ; 95 \%)$ : monotherapy in $17(81 \%)$ and combined therapy with other drugs in 3 $(14 \%)$. The use of pazopanib provided prolonged survival in patients with systemic treatments; the 5-year DSSs were $70 \%$ and $29 \%$ with and without pazopanib, respectively ( $p=0.045$; Figure 3 B). Overall, the median survival period in patients who received pazopanib treatment was 69.8 months, whereas patients who received DOX-based cytotoxic chemotherapy had a median survival period of 48.0 months (Figure 3A and $\mathbf{3 B}$ ). In a comparison before and after the approval of pazopanib, we observed a trend toward superior DSS in patients who had a diagnosis and/or treatment for metastatic ASPS after 2012 (5-year, 65\%) compared to those before 2012 (5-year, 58\%; Figure 4), although this did not reach statistical significance ( $p=$ 0.117).

\section{Discussion}

Although ASPS has greater metastatic potential than other soft-tissue sarcomas, the natural history of the tumor appears to be indolent [18]. Overall, the 5-year DSSs for localized and metastatic ASPS in this study were $86 \%$ and $62 \%$, respectively, which are comparable to the previous studies (Table 5). For localized ASPS, a 5 -year survival rate of approximately $60 \%$ was reported in 1989 by Lieberman et al. [4], while similar results have been observed almost 30 years later in the more recent series $[3,17,19,30]$. In a recent study using the National Cancer Database (USA), a 5-year survival rate of $73 \%$ was reported in 83 patients with localized disease [17]. These data urge the innovation of more effective neoadjuvant/adjuvant therapy for localized ASPS. For metastatic ASPS, Lieberman et al. reported a 5-year survival rate of $22 \%$ in 1989 , while a similar percentage (5-year, 20\%) was noted in 2001 by Portea et al. [2]. Recent series have described more favorable outcomes, and Flores et al. reported a 5-year survival rate of $61 \%$ in 38 patients with metastatic disease [30]. The improvement in survival may be attributed to the introduction of the newly targeted therapies, although this should be confirmed using a larger cohort of patients. Indeed, our data show a trend toward superior DSS, despite no statistical significance, after the approval of pazopanib for advanced soft-tissue sarcomas in 2012. 
For localized ASPS, complete surgical resection appears to be the only curative treatment. In this study, we observed no clinical benefit of neoadjuvant/adjuvant cytotoxic chemotherapy. These data were consistent with the published literature, in that most studies revealed resistance to conventional cytotoxic chemotherapy $[2,8,16,18,31,32]$ with a complete or partial remission rate of less than $10 \%$ [33]. Of note, neoadjuvant/adjuvant radiotherapy has been described to be more effective for local treatment compared to surgery alone $[3,30]$. However, in this study, we could not evaluate the effect of adjuvant radiotherapy because of the limited number of patients who received it $(n=2)$. Of note, favorable local controls in the current cohort could be explained by no intralesional resection of the tumor registered in the BSTTR Database.

No curative therapy has been devised for metastatic ASPS. Although DOX remains standard first-line therapy for soft-tissue sarcomas [34-36], our data confirmed no survival benefit by the DOX-based cytotoxic chemotherapy regimens for metastatic ASPS. Considering the refractoriness of ASPS to conventional cytotoxic chemotherapy, targeted therapy appears to be an attractive alternative. In this study, pazopanib provided a survival benefit, with a median DSS of 69.8 months among those who received systemic therapies. Recent studies have documented the antitumor activity of pazopanib in metastatic ASPS [37-41]. Oh et al. retrospectively analyzed the outcomes of pazopanib treatment in patients with advanced ASPS $(n=10)$ and reported a median overall survival of 48 months, which was favorable compared to the other histological subtypes [39]. Moreover, Jagodzińska-Mucha et al. confirmed the long-term efficacy of sunitinib, an antiangiogenic molecule, in patients with metastatic ASPS ( $n=15)$, with a median overall survival of 56 months [42]. Although the effect of sunitinib could not be evaluated in this study because of the limited number of patients treated with this drug $(n=1)$, previous studies suggest these antiangiogenics could be a putative therapeutic option in the first-line treatment of metastatic ASPS [43]. Recent studies have also demonstrated a promising role of immune checkpoint inhibitors [27, 44, 45]. However, we could not evaluate the therapeutic efficacy of the immunotherapies or targeted drugs other than pazopanib because of the limited number of patients treated with these drugs. Therefore, further studies are warranted to fully evaluate the role of these targeted therapies and immunotherapies for metastatic ASPS.

ASPS is characterized by a high incidence of brain metastasis compared to other subtypes of soft-tissue sarcoma [33]. In this study, brain metastasis was observed in $11 \%$ of patients with metastatic ASPS and occurred in $6 \%$ of patients with localized ASPS, which was comparable to the published literature [2, 17]. These data suggest that intracranial imaging should be added to the routine imaging studies mentioned in the current practice guidelines [34-36]. Brain metastases are mostly observed as a component of disseminated disease [2, 5], and thus, the overall prognosis is poor [46]. In our series, brain metastases occurred as a manifestation of disseminated disease in patients with metastatic ASPS, but the presence of brain metastasis did not affect survival compared to those with metastases at the other sites. Ogura et al. reported favorable local control of brain metastases by Gamma Knife in four patients, with a median progression-free period of 12 months [16]. These patients may be included in this patient cohort, but the data regarding the treatment for brain metastases were not available in the STTR Database. A recent report by Malouf et al. described low efficacy of the antiangiogenic therapies for brain metastasis of ASPS [47], indicating resistance to currently available drugs. There is a need to develop agents with high central nervous system penetrance or specific multimodal therapeutic strategies for brain metastasis of ASPS. 
We acknowledge several limitations of this study. First, the BSTTR Database do not include the exact doses and toxicity of systemic therapies and radiotherapy. Thus, we could not evaluate the efficacy and safety of these therapies precisely based on the number of administrations. Second, the follow-up period was relatively short, with a mean period of 31.5 months; this appears to be common in studies using the large databases [3, 17], and longer follow-up may lead to a decrease in disease-specific death. Third, the information regarding which metastatic site was resected were unavailable if the patients had multiple metastases. Forth, the possibility of a duplicate registration was not excluded if a patient received care at more than one hospital. However, the STTR is designed to automatically exclude the cases if they were referred for "second opinion/only observation after treatment in the previous hospital" to avoid duplicate reporting. Finally, we acknowledge a possibility that some patients who received care at non-JOA-certified hospitals might not be registered in the database because the registry is not mandatory for these institutions. Despite these limitations, we believe that this study is valuable in that the STTR Database is a nationwide sarcoma-specific registry in Japan, presenting the national trend and outcomes in the era of modern multidisciplinary treatment, which is unique compared to international trends and outcomes.

In summary, ASPS is a unique subtype of soft-tissue sarcoma, with a high metastatic rate at presentation but an indolent clinical course. Brain metastases are relatively frequent, necessitating continuous evaluation with head computed tomography in addition to routine radiological screening during the follow-up. For localized ASPS, complete resection with negative margins is the only curative therapy, and no survival benefit of adjuvant chemotherapy and/or radiotherapy was confirmed. For advanced ASPS, use of pazopanib provided prolonged survival compared to the conventional cytotoxic chemotherapy among those who were treated with systemic therapy. A trend toward prolonged survival after the introduction of the targeted drugs encourages continued efforts to develop novel therapeutic options for care.

\section{Abbreviations}

ASPS, alveolar soft part sarcoma; DSS, disease-specific survival; HR, hazard ratio; HIF-1a, hypoxia-inducible factor 1a; VEGF, vascular endothelial growth factor; MET/HGFR, hepatocyte growth factor receptor; PD-1, programmed death 1; PD-L1, programmed death 1 ligand; CTLA-4, cytotoxic T-lymphocyte-associated antigen 4; BSTTR, Bone and Soft-Tissue Tumor Registry; JOA, Japanese Orthopaedic Association; AJCC, American Joint Committee on Cancer; MFS, metastasis-free survival

\section{Declarations}

\section{Ethics approval and consent to participate}

This study was approved by the Institutional Review Board of the Japanese Orthopedic Association. Since the database is de-identified, informed consent was not mandated by the Ethics Guidelines for Human Subject Medical Research and the requirement for informed consent was waived by the Institutional Review Board.

\section{Consent for publication}


Since the database is de-identified, the requirement for consent to publish personal information about an individual was waived.

\section{Availability of data and material}

The datasets that support the findings of this study are available on request from the Japanese Orthopedic Association committee.

\section{Competing interests}

The authors declare that they have no competing interests.

\section{Funding}

This work was supported by JSPS KAKENHI Grant Number $19 \mathrm{H} 03784$.

\section{Authors' contributions}

TF, Study concepts, Study design, Data acquisition, Data analysis and interpretation, Statistical analysis, Manuscript writing; EN, Data interpretation, Manuscript editing, Manuscript review; TK, Data interpretation, Manuscript editing, Manuscript review; TO, Data interpretation, Manuscript editing, Manuscript review; AK, Study concepts, Data acquisition, Quality control of data and algorithms, Data interpretation, Manuscript editing, Manuscript review, Study supervision.

\section{Acknowledgements}

We appreciate all of the medical staff who participated in the BSTTR and all of the patients whose data were recorded, without whom the registry would have not been established. We also acknowledge Ms. Kiyoka Ishihama for her administrative support with the registry.

\section{Reference}

1. Christopherson WM, Foote Jr FW, Stewart FW: Alveolar soft-part sarcomas. Structurally characteristic tumors of uncertain histogenesis. Cancer 1952, 5(1):100-111.

2. Portera Jr CA, Ho V, Patel SR, Hunt KK, Feig BW, Respondek PM, Yasko AW, Benjamin RS, Pollock RE, Pisters PW: Alveolar soft part sarcoma: clinical course and patterns of metastasis in 70 patients treated at a single institution. Cancer 2001, 91(3):585-591.

3. Wang H, Jacobson A, Harmon DC, Choy E, Hornicek FJ, Raskin KA, Chebib IA, DeLaney TF, Chen YL: Prognostic factors in alveolar soft part sarcoma: A SEER analysis. Journal of surgical oncology 2016, 113(5):581-586.

4. Lieberman PH, Brennan MF, Kimmel M, Erlandson RA, Garin-Chesa P, Flehinger BY: Alveolar soft-part sarcoma. A clinico-pathologic study of half a century. Cancer1989, 63(1):1-13. 
5. Ogose A, Yazawa Y, Ueda T, Hotta T, Kawashima H, Hatano H, Morita T, Japanese Musculoskeletal Oncology G: Alveolar soft part sarcoma in Japan: multi-institutional study of 57 patients from the Japanese Musculoskeletal Oncology Group. Oncology 2003, 65(1):7-13.

6. WHO_Classification_of_Tumours_Editorial_Board: WHO classification of tumours of soft tissue and bone, 5th edition. International agency for research on cancer, Lyon 2020.

7. Font RL, Jurco III S, Zimmerman LE: Alveolar soft-part sarcoma of the orbit: a clinicopathologic analysis of seventeen cases and a review of the literature. Human pathology 1982, 13(6):569-579.

8. Pappo AS, Parham DM, Cain A, Luo X, Bowman LC, Furman WL, Rao BN, Pratt CB: Alveolar soft part sarcoma in children and adolescents: clinical features and outcome of 11 patients. Medical and Pediatric Oncology: The Official Journal of SIOP-International Society of Pediatric Oncology (Societé Internationale d'Oncologie Pédiatrique 1996, 26(2):81-84.

9. Casanova M, Ferrari A, Bisogno G, Cecchetto G, Basso E, De Bernardi B, Indolfi P, Bellani FF, Carli M: Alveolar soft part sarcoma in children and adolescents: A report from the Soft-Tissue Sarcoma Italian Cooperative Group. Annals of Oncology 2000, 11(11):1445-1449.

10. FUREY JG, BARRETT DL, SEIBERT RH: Alveolar soft-part sarcoma: report of a case presenting as a sacral bone tumor. JBJS 1969, 51(1):185-190.

11. O'Toole RV, Tuttle SE, Lucas JG, Sharma HM: Alveolar soft part sarcoma of the vagina: an immunohistochemical and electron microscopic study. International journal of gynecological pathology: official journal of the International Society of Gynecological Pathologists 1985, 4(3):258-265.

12. Nolan N, Gaffney E: Alveolar soft part sarcoma of the uterus. Histopathology 1990, 16(1):97-99.

13. Yagihashi S, Yagihashi N, Hase Y, Nagai K, Alguacil-Garcia A: Primary alveolar soft-part sarcoma of stomach. The American journal of surgical pathology 1991, 15(4):399-406.

14. Durkin RC, Johnston JO: Alveolar soft part sarcoma involving the ilium: a case report. Clinical Orthopaedics and Related Research ${ }^{\circledR}$ 1999, 359:197-202.

15. Fletcher M: Primary alveolar soft part sarcoma of bone. Histopathology 1999, 35(5):411-417.

16. Ogura K, Beppu Y, Chuman H, Yoshida A, Yamamoto N, Sumi M, Kawano H, Kawai A: Alveolar soft part sarcoma: a single-center 26-patient case series and review of the literature. Sarcoma 2012, 2012:907179.

17. Hagerty BL, Aversa J, Diggs LP, Dominguez DA, Ayabe RI, Blakely AM, Davis JL, Luu C, Hernandez JM: Characterization of alveolar soft part sarcoma using a large national database. Surgery 2020, 168(5):825830.

18. Paoluzzi L, Maki RG: Diagnosis, Prognosis, and Treatment of Alveolar Soft-Part Sarcoma: A Review. JAMA Oncol 2019, 5(2):254-260. 
19. Penel N, Robin Y-M, Blay J-Y: Personalised management of alveolar soft part sarcoma: a promising phase 2 study. The Lancet Oncology 2019, 20(6):750-752.

20. Lazar AJ, Das P, Tuvin D, Korchin B, Zhu Q, Jin Z, Warneke CL, Zhang PS, Hernandez V, Lopez-Terrada D: Angiogenesis-promoting gene patterns in alveolar soft part sarcoma. Clinical Cancer Research 2007, 13(24):7314-7321.

21. Penel N, Coindre JM, Giraud A, Terrier P, Ranchere-Vince D, Collin F, Guellec SLE, Bazille C, Lae M, de Pinieux $\mathrm{G}$ et al: Presentation and outcome of frequent and rare sarcoma histologic subtypes: A study of 10,262 patients with localized visceral/soft tissue sarcoma managed in reference centers. Cancer 2018, 124(6):1179-1187.

22. Nakano K, Takahashi S: Current molecular targeted therapies for bone and soft tissue sarcomas. International journal of molecular sciences 2018, 19(3):739.

23. van der Graaf WT, Blay J-Y, Chawla SP, Kim D-W, Bui-Nguyen B, Casali PG, Schöffski P, Aglietta M, Staddon AP, Beppu Y: Pazopanib for metastatic soft-tissue sarcoma (PALETTE): a randomised, double-blind, placebocontrolled phase 3 trial. The Lancet 2012, 379(9829):1879-1886.

24. Kawai A, Yonemori K, Takahashi S, Araki N, Ueda T: Systemic therapy for soft tissue sarcoma: proposals for the optimal use of pazopanib, trabectedin, and eribulin. Advances in therapy 2017, 34(7):1556-1571.

25. Ayodele O, Razak A: Immunotherapy in soft-tissue sarcoma. Current Oncology 2020, 27(s1):17-23.

26. Martín-Broto J, Moura DS, Van Tine BA: Facts and hopes in immunotherapy of soft-tissue sarcomas. Clinical Cancer Research 2020, 26(22):5801-5808.

27. Wilky BA, Trucco MM, Subhawong TK, Florou V, Park W, Kwon D, Wieder ED, Kolonias D, Rosenberg AE, Kerr DA et al: Axitinib plus pembrolizumab in patients with advanced sarcomas including alveolar soft-part sarcoma: a single-centre, single-arm, phase 2 trial. The Lancet Oncology 2019, 20(6):837-848.

28. Amin MB, Edge SB: AJCC cancer staging manual: springer; 2017.

29. Enneking WF, Spanier SS, Goodman MA: A system for the surgical staging of musculoskeletal sarcoma. Clinical orthopaedics and related research 1980, 153:106-120.

30. Flores RJ, Harrison DJ, Federman NC, Furman WL, Huh WW, Broaddus EG, Okcu MF, Venkatramani R: Alveolar soft part sarcoma in children and young adults: A report of 69 cases. Pediatric blood \& cancer 2018 , 65(5):e26953.

31. Folpe A, Deyrup A: Alveolar soft-part sarcoma: a review and update. Journal of clinical pathology 2006, 59(11):1127-1132.

32. Pennacchioli E, Fiore M, Collini P, Radaelli S, Dileo P, Stacchiotti S, Casali PG, Gronchi A: Alveolar soft part sarcoma: clinical presentation, treatment, and outcome in a series of 33 patients at a single institution. Annals of surgical oncology 2010, 17(12):3229-3233. 
33. Reichardt P, Lindner T, Pink D, Thuss-Patience P, Kretzschmar A, Dörken B: Chemotherapy in alveolar soft part sarcomas: what do we know? European Journal of Cancer 2003, 39(11):1511-1516.

34. Dangoor A, Seddon B, Gerrand C, Grimer R, Whelan J, Judson I: UK guidelines for the management of soft tissue sarcomas. Clinical sarcoma research 2016, 6:20.

35. Casali PG, Abecassis N, Aro HT, Bauer S, Biagini R, Bielack S, Bonvalot S, Boukovinas I, Bovee J, Brodowicz T et al: Soft tissue and visceral sarcomas: ESMO-EURACAN Clinical Practice Guidelines for diagnosis, treatment and follow-up. Annals of oncology : official journal of the European Society for Medical Oncology / ESMO 2018, 29(Suppl 4):iv51-iv67.

36. von Mehren M, Randall RL, Benjamin RS, Boles S, Bui MM, Ganjoo KN, George S, Gonzalez RJ, Heslin MJ, Kane JM et al: Soft Tissue Sarcoma, Version 2.2018, NCCN Clinical Practice Guidelines in Oncology. J Natl Compr Canc Netw 2018, 16(5):536-563.

37. Kim M, Kim TM, Keam B, Kim YJ, Paeng JC, Moon KC, Kim DW, Heo DS: A Phase II Trial of Pazopanib in Patients with Metastatic Alveolar Soft Part Sarcoma. Oncologist 2019, 24(1):20-e29.

38. Liu J, Fan Z, Li S, Gao T, Xue R, Bai C, Zhang L, Tan Z, Fang Z: Target therapy for metastatic alveolar soft part sarcoma: a retrospective study with 47 cases. Ann Transl Med 2020, 8(22):1493.

39. Oh CR, Hong JY, Kim JH, Lee JS, Kim HS, Kim TW, Ahn JH, Kim JE: Real-World Outcomes of Pazopanib Treatment in Korean Patients with Advanced Soft Tissue Sarcoma: A Multicenter Retrospective Cohort Study. Target Oncol 2020, 15(4):485-493.

40. Shido Y, Matsuyama Y: Advanced Alveolar Soft Part Sarcoma Treated with Pazopanib over Three Years. Case Rep Oncol Med 2017, 2017:3738562.

41. Stacchiotti S, Mir O, Le Cesne A, Vincenzi B, Fedenko A, Maki RG, Somaiah N, Patel S, Brahmi M, Blay JY: Activity of pazopanib and trabectedin in advanced alveolar soft part sarcoma. The oncologist 2018, 23(1):62.

42. Jagodzinska-Mucha P, Switaj T, Kozak K, Kosela-Paterczyk H, Klimczak A, Lugowska I, Rogala P, Wagrodzki M, Falkowski S, Rutkowski P: Long-term results of therapy with sunitinib in metastatic alveolar soft part sarcoma. Tumori 2017, 103(3):231-235.

43. Urakawa H, Kawai A, Goto T, Hiraga H, Ozaki T, Tsuchiya H, Nakayama R, Naka N, Matsumoto Y, Kobayashi $\mathrm{E}$ et al: Phase II trial of pazopanib in patients with metastatic or unresectable chemoresistant sarcomas: A Japanese Musculoskeletal Oncology Group study. Cancer Sci 2020, 111(9):3303-3312.

44. Liu J, Fan Z, Bai C, Li S, Xue R, Gao T, Zhang L, Tan Z, Fang Z: Real-world experience with pembrolizumab in patients with advanced soft tissue sarcoma. Ann Transl Med 2021, 9(4):339.

45. Mariuk-Jarema A, Kosela-Paterczyk H, Rogala P, Klimczak A, Wagrodzki M, Maksymiuk B, Rutkowski P: A durable complete response to immunotherapy in a patient with metastatic alveolar soft part sarcoma. Tumori 2020, 106(6):NP9-NP13. 
46. Ogose A, Morita T, Hotta T, Kobayashi H, Otsuka H, Hirata Y, Yoshida S: Brain metastases in musculoskeletal sarcomas. Japanese journal of clinical oncology 1999, 29(5):245-247.

47. Malouf GG, Beinse G, Adam J, Mir O, Chamseddine AN, Terrier P, Honore C, Spano JP, Italiano A, Kurtz JE et al: Brain Metastases and Place of Antiangiogenic Therapies in Alveolar Soft Part Sarcoma: A Retrospective Analysis of the French Sarcoma Group. The Oncologist 2019, 24(7):980-988.

\section{Tables}

Table 1. Clinical characteristics and univariate analysis predictors for DSS 


\begin{tabular}{|c|c|c|c|c|}
\hline Variable & $\mathrm{N}$ & $\%$ & 5-year DSS & $p$ value \\
\hline Total & 120 & 100 & $68 \%$ & - \\
\hline Age (median: 27 years) & & & & 0.630 \\
\hline$\leq 25$ years & 50 & $42 \%$ & $73 \%$ & \\
\hline$>25$ years & 70 & $58 \%$ & $65 \%$ & \\
\hline Sex & & & & 0.429 \\
\hline Male & 42 & $35 \%$ & $62 \%$ & \\
\hline Female & 78 & $65 \%$ & $72 \%$ & \\
\hline Tumor site & & & & 0.517 \\
\hline Lower extremity & 74 & $62 \%$ & $72 \%$ & \\
\hline Upper extremity & 11 & $9 \%$ & $80 \%$ & \\
\hline Trunk & 34 & $28 \%$ & $63 \%$ & \\
\hline Head and neck & 1 & $1 \%$ & $0 \%$ & \\
\hline Tumor depth & & & & 0.922 \\
\hline Superficial & 7 & $6 \%$ & $83 \%$ & \\
\hline Deep & 113 & $94 \%$ & $68 \%$ & \\
\hline Tumor size (median: $7.0 \mathrm{~cm}$ ) & & & & 0.200 \\
\hline$\leq 5 \mathrm{~cm}$ & 27 & $23 \%$ & $94 \%$ & \\
\hline$>5 \mathrm{~cm}, \leq 10 \mathrm{~cm}$ & 67 & $56 \%$ & $63 \%$ & \\
\hline$>10 \mathrm{~cm}$ & 26 & $22 \%$ & $65 \%$ & \\
\hline Stage (AJCC 8th) & & & & 0.061 \\
\hline II & 16 & $13 \%$ & $100 \%$ & \\
\hline IIIA & 13 & $11 \%$ & $100 \%$ & \\
\hline IIIB & 5 & $4 \%$ & $0 \%$ & \\
\hline IV & 86 & $72 \%$ & $62 \%$ & \\
\hline Metastasis at diagnosis & & & & 0.019 \\
\hline No & 34 & $28 \%$ & $86 \%$ & \\
\hline Yes & 86 & $72 \%$ & $62 \%$ & \\
\hline
\end{tabular}

Table 2. Clinical characteristics according to the presence of distant metastasis at diagnosis 


\begin{tabular}{|c|c|c|c|c|c|}
\hline \multirow[t]{2}{*}{ Variable } & \multicolumn{2}{|c|}{ Localized ASPS $(n=34)$} & \multicolumn{2}{|c|}{ Metastatic ASPS $(n=86)$} & \multirow[t]{2}{*}{$p$ value } \\
\hline & $\mathrm{N}$ & $\%$ & $\mathrm{~N}$ & $\%$ & \\
\hline Age & & & & & 0.023 \\
\hline$\leq 25$ years & 20 & $40 \%$ & 30 & $60 \%$ & \\
\hline$>25$ years & 14 & $20 \%$ & 56 & $80 \%$ & \\
\hline Sex & & & & & 0.289 \\
\hline Male & 9 & $21 \%$ & 33 & $79 \%$ & \\
\hline Female & 25 & $32 \%$ & 53 & $68 \%$ & \\
\hline Tumor site & & & & & 0.520 \\
\hline Lower extremity & 19 & $26 \%$ & 55 & $74 \%$ & \\
\hline Upper extremity & 5 & $46 \%$ & 6 & $55 \%$ & \\
\hline Trunk & 10 & $29 \%$ & 24 & $71 \%$ & \\
\hline Head and neck & 0 & $0 \%$ & 1 & $100 \%$ & \\
\hline Tumor depth & & & & & 0.002 \\
\hline Superficial & 6 & $86 \%$ & 1 & $14 \%$ & \\
\hline Deep & 28 & $25 \%$ & 85 & $75 \%$ & \\
\hline Tumor size & & & & & $<0.001$ \\
\hline$\leq 5 \mathrm{~cm}$ & 16 & $59 \%$ & 11 & $41 \%$ & \\
\hline$>5 \mathrm{~cm}, \leq 10 \mathrm{~cm}$ & 13 & $19 \%$ & 54 & $81 \%$ & \\
\hline$>10 \mathrm{~cm}$ & 5 & $19 \%$ & 21 & $81 \%$ & \\
\hline
\end{tabular}

Table 3. Univariate and multivariate analysis of predictors for DSS and MFS in patients with localized ASPS 


\begin{tabular}{|c|c|c|c|c|c|c|}
\hline Variable & $\mathrm{N}$ & $\%$ & 5-year DSS & $p$ value & 5-year MFS & $p$ value \\
\hline Age (median: years) & & & & 0.527 & & 0.947 \\
\hline$\leq 25$ years & 16 & $55 \%$ & $100 \%$ & & $61 \%$ & \\
\hline$>25$ years & 13 & $45 \%$ & $80 \%$ & & $0 \%$ & \\
\hline Sex & & & & 0.114 & & 0.240 \\
\hline Male & 7 & $24 \%$ & $50 \%$ & & $29 \%$ & \\
\hline Female & 22 & $76 \%$ & $100 \%$ & & $21 \%$ & \\
\hline Tumor site & & & & NA & & 0.567 \\
\hline Lower extremity & 18 & $62 \%$ & $83 \%$ & & $25 \%$ & \\
\hline Upper extremity & 4 & $14 \%$ & NA & & $50 \%$ & \\
\hline Trunk & 7 & $24 \%$ & $100 \%$ & & $0 \%$ & \\
\hline Tumor depth & & & & 0.683 & & 0.630 \\
\hline Superficial & 5 & $17 \%$ & $100 \%$ & & $0 \%$ & \\
\hline Deep & 24 & $83 \%$ & $83 \%$ & & $25 \%$ & \\
\hline Tumor size & & & & 0.021 & & 0.391 \\
\hline$\leq 5 \mathrm{~cm}$ & 13 & $45 \%$ & $100 \%$ & & $76 \%$ & \\
\hline$>5 \mathrm{~cm}$ & 16 & $55 \%$ & $56 \%$ & & $22 \%$ & \\
\hline Type of surgery & & & & 0.076 & & 0.082 \\
\hline Limb-salvage & 27 & $93 \%$ & $100 \%$ & & $21 \%$ & \\
\hline Amputation & 1 & $3 \%$ & $0 \%$ & & $0 \%$ & \\
\hline Unknown & 1 & $3 \%$ & NA & & $0 \%$ & \\
\hline Resection margin & & & & NA & & 0.439 \\
\hline Intralesional & 0 & - & - & & - & \\
\hline Marginal & 3 & $7 \%$ & NA & & NA & \\
\hline Wide & 26 & $90 \%$ & $100 \%$ & & $19 \%$ & \\
\hline Other (radical) & 1 & $3 \%$ & $0 \%$ & & $0 \%$ & \\
\hline $\mathrm{RT}$ & & & & NA & & 0.689 \\
\hline No & 27 & $93 \%$ & $86 \%$ & & $19 \%$ & \\
\hline Adjuvant $^{1}$ & 2 & $7 \%$ & NA & & NA & \\
\hline Chemotherapy & & & & 0.683 & & 0.014 \\
\hline
\end{tabular}




\begin{tabular}{ccccc} 
No & 27 & $93 \%$ & $83 \%$ & $20 \%$ \\
\hline Neoadjuvant/adjuvant ${ }^{2}$ & 2 & $7 \%$ & $100 \%$ & $0 \%$ \\
\hline${ }^{1}$ Adjuvant use = 2; ${ }^{2}$ Neoadjuvant use = 1, adjuvant use = 3; NA, not available
\end{tabular}

Table 4. Univariate and multivariate analysis of predictors for DSS in patients with metastatic ASPS 


\begin{tabular}{|c|c|c|c|c|}
\hline Variable & $\mathrm{N}$ & $\%$ & 5-year DSS & $p$ value \\
\hline Age (median: years) & & & & 0.911 \\
\hline$\leq 25$ years & 30 & $35 \%$ & $64 \%$ & \\
\hline$>25$ years & 56 & $65 \%$ & $60 \%$ & \\
\hline Sex & & & & 0.997 \\
\hline Male & 33 & $38 \%$ & $63 \%$ & \\
\hline Female & 53 & $62 \%$ & $61 \%$ & \\
\hline Tumor site & & & & 0.542 \\
\hline Lower extremity & 55 & $64 \%$ & $68 \%$ & \\
\hline Upper extremity & 6 & $7 \%$ & $75 \%$ & \\
\hline Trunk & 24 & $28 \%$ & $55 \%$ & \\
\hline Head and neck & 1 & $1 \%$ & $0 \%$ & \\
\hline Tumor depth & & & & 0.006 \\
\hline Superficial & 1 & $1 \%$ & $0 \%$ & \\
\hline Deep & 85 & $99 \%$ & $63 \%$ & \\
\hline Tumor size & & & & 0.719 \\
\hline$\leq 5 \mathrm{~cm}$ & 11 & $13 \%$ & $83 \%$ & \\
\hline$>5 \mathrm{~cm}, \leq 10 \mathrm{~cm}$ & 54 & $63 \%$ & $54 \%$ & \\
\hline$>10 \mathrm{~cm}$ & 21 & $24 \%$ & $76 \%$ & \\
\hline Resection of the primary site & & & & 0.559 \\
\hline No & 29 & $34 \%$ & $51 \%$ & \\
\hline Yes & 57 & $66 \%$ & $68 \%$ & \\
\hline Resection of the metastatic site & & & & 0.143 \\
\hline No & 75 & $87 \%$ & $62 \%$ & \\
\hline Yes & 11 & $13 \%$ & $67 \%$ & \\
\hline RT & & & & 0.614 \\
\hline No & 73 & $85 \%$ & $61 \%$ & \\
\hline For primary lesion & 4 & $5 \%$ & $38 \%$ & \\
\hline For metastasis & 9 & $11 \%$ & $73 \%$ & \\
\hline Chemotherapy & & & & 0.470 \\
\hline
\end{tabular}




\begin{tabular}{llll} 
No & 38 & $44 \%$ & $73 \%$ \\
\hline Conventional chemotherapeutic drug & 14 & $16 \%$ & $34 \%$ \\
\hline Targeted drug & 19 & $22 \%$ & $66 \%$ \\
\hline Conventional chemotherapy + targeted therapy & 11 & $13 \%$ & $55 \%$ \\
\hline Unknown & 4 & $5 \%$ & $\mathrm{NA}$ \\
\hline Regimen (information available; $\mathrm{n}=44)$ & & & \\
\hline DoX-based regimen & & & \\
\hline Yes & 23 & $27 \%$ & $39 \%$ \\
\hline No & 21 & $24 \%$ & $75 \%$ \\
\hline Use of pazopanib & & & \\
\hline Yes & 27 & $31 \%$ & $70 \%$ \\
\hline No & 17 & $20 \%$ & $29 \%$ \\
\hline
\end{tabular}

Abbreviation: RT, radiotherapy, DOX, doxorubicin; NA, not available

Table 5. ASPS and survival outcomes in localized and metastatic disease 


\begin{tabular}{|c|c|c|c|c|c|c|}
\hline \multirow[t]{2}{*}{ Source } & \multirow{2}{*}{$\begin{array}{l}\text { No. of patients } \\
\text { (localized/metastatic) }\end{array}$} & \multicolumn{3}{|c|}{ 5-year survival } & \multirow{2}{*}{$\begin{array}{l}\text { Prognostic } \\
\text { factor }\end{array}$} & \multirow[t]{2}{*}{ Comments } \\
\hline & & Overall & Localized & Metastatic & & \\
\hline \multirow{2}{*}{$\begin{array}{l}\text { Lieberman } \\
\text { et al, } 1989\end{array}$} & 91 & \multirow[t]{2}{*}{$57 \%$} & \multirow[t]{2}{*}{$60 \%$} & \multirow[t]{2}{*}{$22 \%$} & \multirow{2}{*}{$\begin{array}{l}\text { Age, } \\
\text { metastasis }\end{array}$} & \multirow{2}{*}{$\begin{array}{l}\text { Increased } \\
\text { rate of } \\
\text { metastasis } \\
\text { at } \\
\text { presentation } \\
\text { as the age } \\
\text { increases }\end{array}$} \\
\hline & $(69 / 22)$ & & & & & \\
\hline \multirow{2}{*}{$\begin{array}{l}\text { Casanova } \\
\text { et al, } 2000\end{array}$} & & \multirow[t]{2}{*}{$80 \%$} & \multirow[t]{2}{*}{$91 \%$} & \multirow[t]{2}{*}{ NA } & \multirow[t]{2}{*}{ Size } & \multirow{2}{*}{$\begin{array}{l}\text { Series of } \\
\text { pediatric } \\
\text { patients } \\
\text { (median } \\
\text { age, } 12 \\
\text { years) }\end{array}$} \\
\hline & $(15 / 4)$ & & & & & \\
\hline \multirow{2}{*}{$\begin{array}{l}\text { Portea et } \\
\text { al, } 2001\end{array}$} & 74 & \multirow[t]{2}{*}{$47 \%$} & \multirow[t]{2}{*}{$88 \%$} & \multirow[t]{2}{*}{$20 \%$} & \multirow[t]{2}{*}{ Metastasis } & \multirow{2}{*}{$\begin{array}{l}\text { Brain } \\
\text { metastasis } \\
\text { in } 9 \text { of } 48 \\
\text { patients } \\
(18.8 \%) \text { with } \\
\text { metastatic } \\
\text { disease }\end{array}$} \\
\hline & $(22 / 52)$ & & & & & \\
\hline \multirow{2}{*}{$\begin{array}{l}\text { Ogose et } \\
\text { al, } 2003\end{array}$} & & \multirow[t]{2}{*}{$56 \%$} & \multirow[t]{2}{*}{$81 \%$} & \multirow[t]{2}{*}{$46 \%$} & \multirow{2}{*}{$\begin{array}{l}\text { Metastasis, } \\
\text { size, bone } \\
\text { involvement }\end{array}$} & \multirow{2}{*}{$\begin{array}{l}\text { Bone } \\
\text { involvement } \\
\text { at the } \\
\text { primary site } \\
\text { in 23\% }\end{array}$} \\
\hline & $(20 / 37)$ & & & & & \\
\hline \multirow{2}{*}{$\begin{array}{l}\text { Daigeler et } \\
\text { al, } 2008\end{array}$} & 11 & \multirow[t]{2}{*}{$88 \%$} & \multirow[t]{2}{*}{$88 \%$} & \multirow[t]{2}{*}{-} & \multirow[t]{2}{*}{ None } & \multirow[b]{2}{*}{$\begin{array}{l}\text { Brain and } \\
\text { lung } \\
\text { metastasis } \\
\text { in } 3 \text { of } 3 \\
\text { patients } \\
(100 \%) \text { with } \\
\text { patients } \\
\text { who } \\
\text { developed } \\
\text { metastases }\end{array}$} \\
\hline & $(11 / 0)$ & & & & & \\
\hline \multirow{2}{*}{$\begin{array}{l}\text { Ogura et } \\
\mathrm{al}, 2012\end{array}$} & 26 & \multirow[t]{2}{*}{$64 \%$} & $100 \%$ & $37 \%$ & Size, & Median \\
\hline & $(10 / 16)$ & & & & & months \\
\hline Wang et & 251 & $56 \%$ & $81 \%$ & $41 \%$ & Age, tumor & Improved \\
\hline $\mathrm{dl}, \angle \mathrm{U} / \mathrm{O}$ & $(118 / 108)$ & & & $\begin{array}{l}(\text { surgery+), } \\
10 \% \\
\text { (surgery-) }\end{array}$ & $\begin{array}{l}\text { SIze, } \\
\text { metastasis, } \\
\text { trunk, no } \\
\text { treatment, } \\
\text { only RT } \\
\text { without } \\
\text { surgery }\end{array}$ & $\begin{array}{l}\text { surgery+RT } \\
\text { (localized) } \\
\text { Improved } \\
\text { OS by } \\
\text { primary site } \\
\text { surgery } \\
\text { (metastatic) }\end{array}$ \\
\hline $\begin{array}{l}\text { Brennan } \\
\text { et al. } 2018\end{array}$ & 22 & $100 \%$ & $100 \%$ & $100 \%$ & NA & $\begin{array}{l}\text { Series of } \\
\text { pediatric }\end{array}$ \\
\hline & $(20 / 2)$ & & & & & patients \\
\hline
\end{tabular}


(median age, 11.5 years)

5-year EFS, $94.7 \%$ (localized disease)

\begin{tabular}{|c|c|c|c|c|c|c|}
\hline $\begin{array}{l}\text { Flores et } \\
\text { al, } 2018\end{array}$ & $\begin{array}{l}69 \\
(31 / 38)\end{array}$ & $72 \%$ & $87 \%$ & $61 \%$ & $\begin{array}{l}\text { Age, sex, } \\
\text { metastasis }\end{array}$ & $\begin{array}{l}\text { Series of } \\
\text { pediatric } \\
\text { patients } \\
(<30 \text { years) }\end{array}$ \\
\hline $\begin{array}{l}\text { Hagerty et } \\
\text { al, } 2020\end{array}$ & $\begin{array}{l}293 \\
(83 / 172)\end{array}$ & NA & $\begin{array}{l}73 \% \\
\text { (surgery+) }\end{array}$ & $\begin{array}{l}46 \% \\
\text { (surgery+) }\end{array}$ & $\begin{array}{l}\text { Size, } \\
\text { margin, } \\
\text { metastasis } \\
\text { multimodal } \\
\text { therapy, } \\
\text { hospital } \\
\text { volume }\end{array}$ & $\begin{array}{l}\text { Analysis } \\
\text { from } \\
\text { National } \\
\text { Cancer } \\
\text { Database in } \\
\text { the United } \\
\text { States }\end{array}$ \\
\hline $\begin{array}{l}\text { Current } \\
\text { study, } \\
2021\end{array}$ & $\begin{array}{l}120 \\
(34 / 86)\end{array}$ & $68 \%$ & $86 \%$ & $62 \%$ & Metastasis & $\begin{array}{l}\text { Analysis } \\
\text { from STS } \\
\text { Registry } \\
\text { Database in } \\
\text { Japan }\end{array}$ \\
\hline
\end{tabular}

Abbreviations; OS, overall survival; NA, not available

\section{Figures}

A

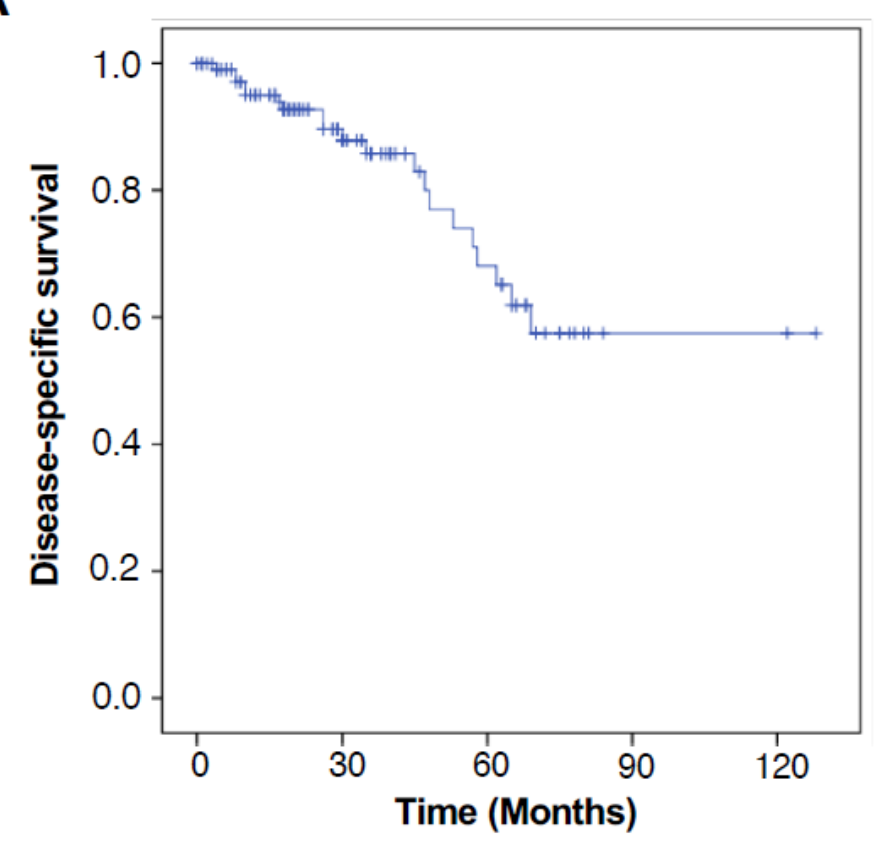

B

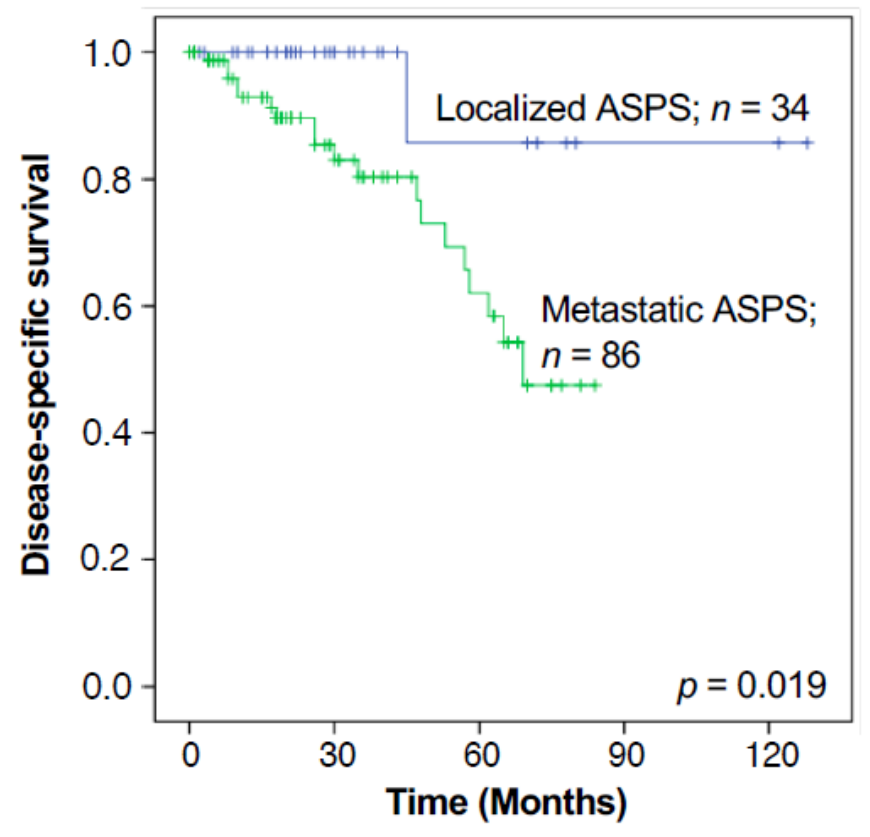

Figure 1 
Kaplan-Meier curves showing the disease-specific survival for all patients studied (A) and localized versus metastatic disease at the time of diagnosis (B).

A

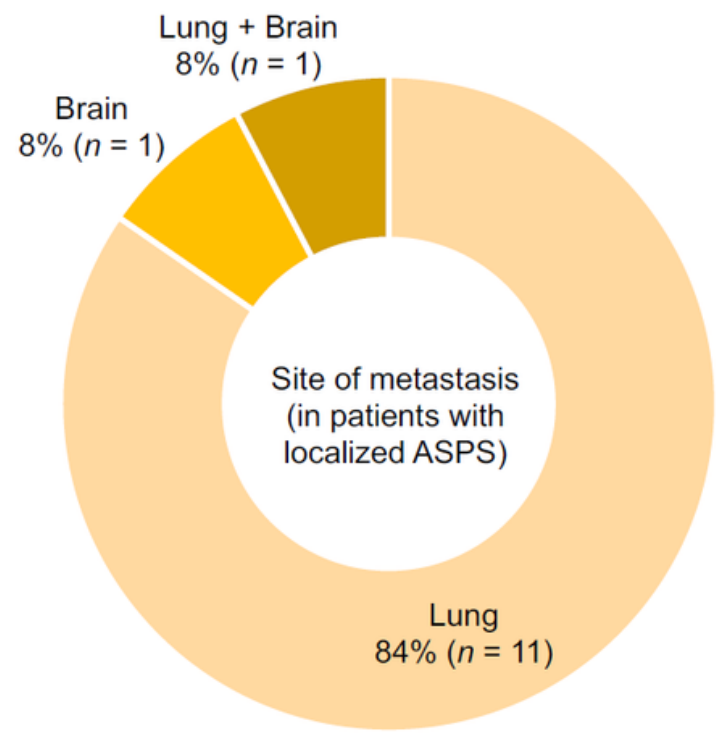

B

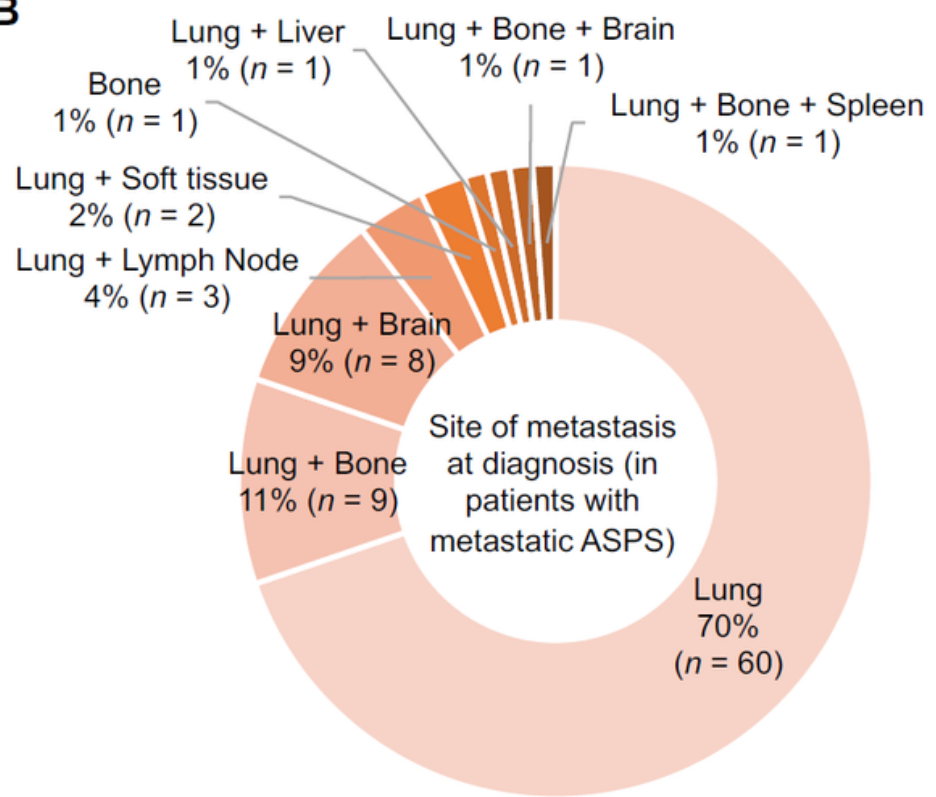

\section{Figure 2}

Site of metastasis developed in patients with localized (A) and metastatic ASPS (B).

A

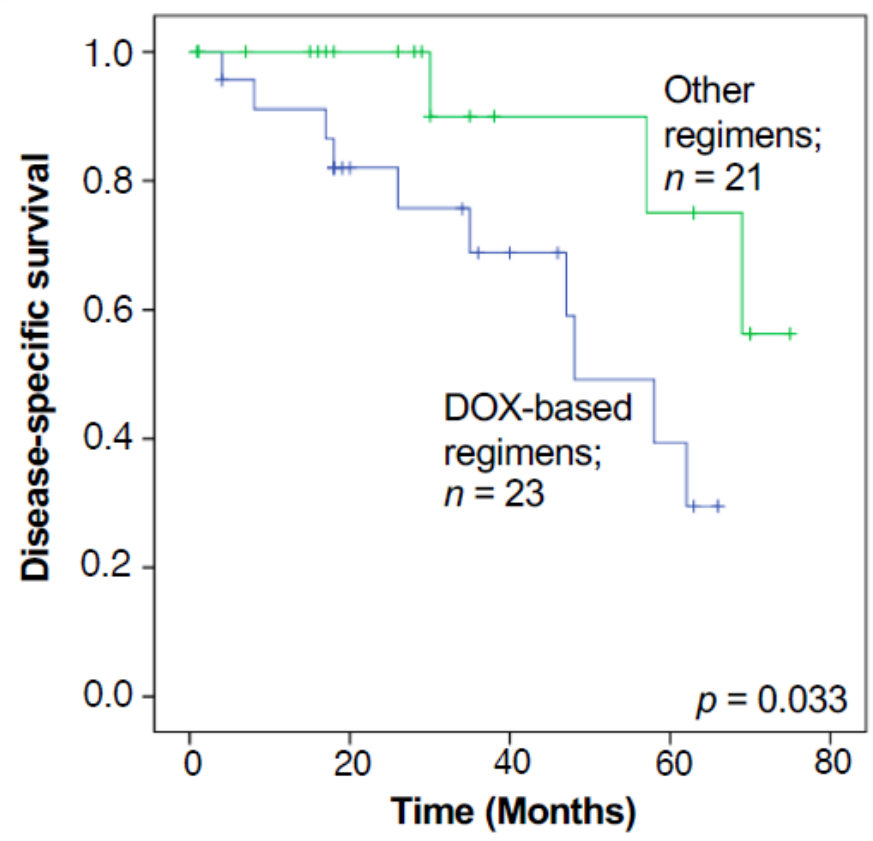

B

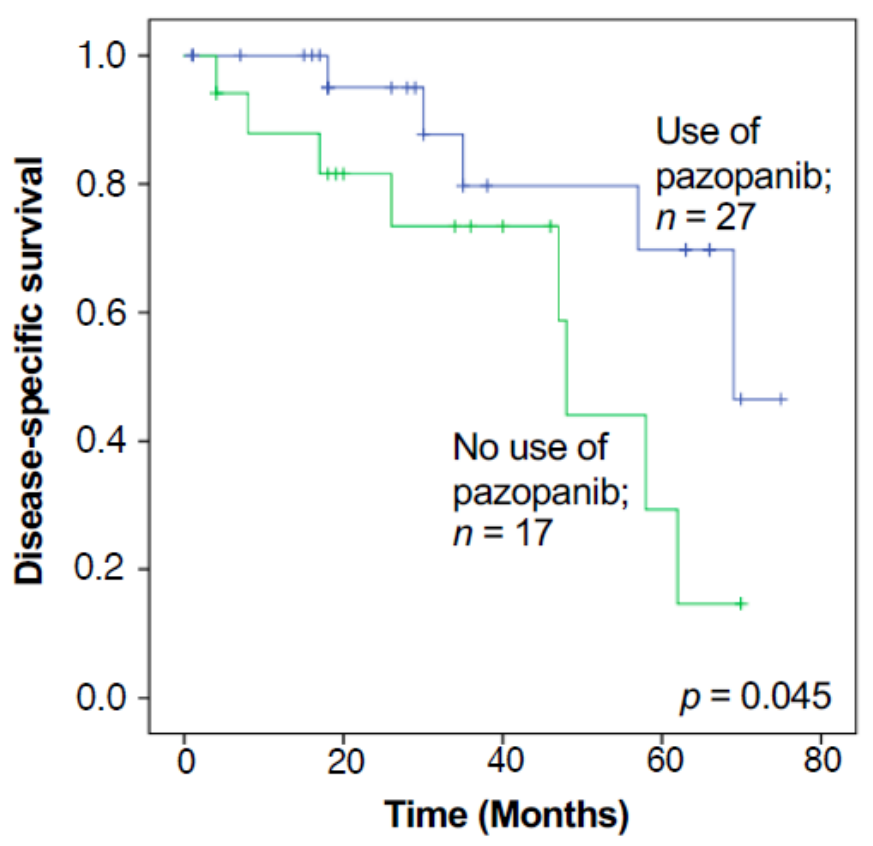

\section{Figure 3}

Kaplan-Meier curves showing the disease-specific survival in patients who received systemic treatments for metastatic ASPS, stratified by the use of doxorubicin (DOX) (A) and pazopanib (B). 


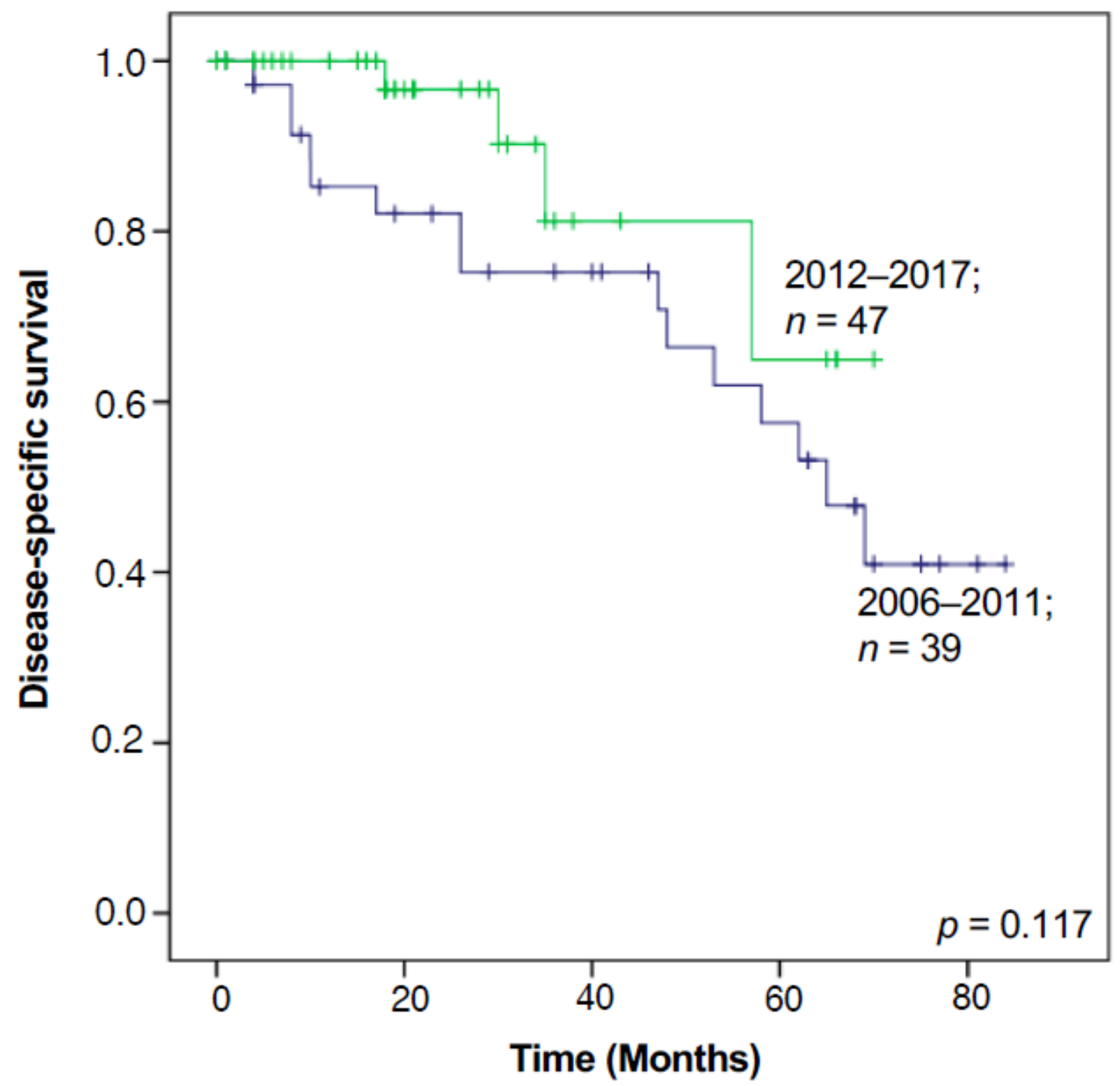

Figure 4

Kaplan-Meier curves showing the disease-specific survival in patients with metastatic ASPS, stratified by the era of treatments; $2006-2011$ versus 2012-2017.

\section{Supplementary Files}

This is a list of supplementary files associated with this preprint. Click to download.

- SupplmentaryTableFinal.pdf 